\title{
School Segregation, Educational Attainment, and Crime: Evidence from the End of Busing in Charlotte-Mecklenburg
}

\section{Citation}

Billings, S. B., D. J. Deming, and J. Rockoff. 2014. "School Segregation, Educational Attainment, and Crime: Evidence from the End of Busing in Charlotte-Mecklenburg." The Quarterly Journal of Economics 129 (1) (February 1): 435-476. doi:10.1093/qje/qjt026. http://dx.doi.org/10.1093/qje/ qjt026.

\section{Published Version}

doi:10.1093/qje/qjt026

\section{Permanent link}

http://nrs.harvard.edu/urn-3:HUL.InstRepos:12308136

\section{Terms of Use}

This article was downloaded from Harvard University's DASH repository, and is made available under the terms and conditions applicable to Open Access Policy Articles, as set forth at http:// nrs.harvard.edu/urn-3:HUL.InstRepos:dash.current.terms-of-use\#OAP

\section{Share Your Story}

The Harvard community has made this article openly available.

Please share how this access benefits you. Submit a story.

Accessibility 


\title{
SCHOOL SEGREGATION, EDUCATIONAL ATTAINMENT, AND CRIME: EVIDENCE FROM THE END OF BUSING IN CHARLOTTE-MECKLENBURG*
}

\author{
STEPHEN B. BILLINGS \\ DAVID J. DEMING \\ JONAH ROCKOFF
}

We study the end of race-based busing in Charlotte-Mecklenburg schools (CMS). In 2001, school boundaries in CMS were redrawn dramatically, and half of students received a new assignment. Using addresses measured prior to the policy change, we compare students in the same neighborhood that lived on opposite sides of a newly drawn boundary. We find that both white and minority students score lower on high school exams when they are assigned to schools with more minority students. We also find decreases in high school graduation and four-year college attendance for whites and large increases in crime for minority males. We conclude that the end of race-based busing widened racial inequality, despite efforts by CMS to mitigate the effect of segregation through compensatory resource allocation. JEL Codes: I20, I24.

\section{INTRODUCTION}

Since the landmark 1954 Supreme Court decision Brown v. Board of Education (347 U.S. 483), schools have been seen by courts and policy makers as a primary social setting in which to address racial inequality. The Brown decision declared "separate but equal" schooling unconstitutional, yet efforts to engineer racial integration through student assignment policy have been highly controversial and not always successful. A 1971 Supreme Court case, Swann v. Charlotte-Mecklenburg Board of Education (402 U.S. 1), held that Mecklenburg County schools were de facto

*We thank Kehinde Ajayi, Josh Angrist, Felipe Barrera-Osorio, Elizabeth Cascio, Caroline Hoxby, Richard Murnane, Amanda Pallais, Sarah Reber, Steven Rivkin, Stephen Ross, Marty West, and seminar participants at the NBER Education Meetings; the AEFP, APPAM, and UEA research conferences; and Elon University, Georgetown University, University of Arkansas, University of Connecticut, University of North Carolina at Greensboro, University of Rochester, University of Tennessee and Vanderbilt University for helpful comments and suggestions. Special thanks to Andy Baxter and Tom Tomberlin at Charlotte-Mecklenburg Schools; Brian Cunningham, Mike Humphrey, Monica Nguyen and Paul Paskoff at the Charlotte-Mecklenburg Police Department; and Julia Rush at the Mecklenburg County Sheriff's Department for their assistance with putting the data together for the project.

(C) The Author(s) 2013. Published by Oxford University Press, on behalf of President and Fellows of Harvard College. All rights reserved. For Permissions, please email: journals .permissions@oup.com

The Quarterly Journal of Economics (2014), 435-476. doi:10.1093/qje/qjt026.

Advance Access publication on September 17, 2013. 
segregated even in the absence of an explicit policy, because neighborhoods were highly segregated, and authorized the use of busing to achieve racial balance in schools.

Race-based busing soon spread to school districts around the country, and court-ordered school desegregation became one of the most ambitious social policies of the twentieth century. Scholars have connected the widespread implementation of school desegregation plans in the late 1960s and 1970s with increased educational attainment for black students (Guryan 2004; Reber 2010), higher income (Ashenfelter et al. 2006; Johnson 2011), improvements in adult health (Johnson 2011), and decreased rates of homicide victimization and arrests (Weiner et al. 2009). Many studies have found that segregation widens the racial test score gap, with most (but not all) concluding that schools play at least as important a role as neighborhoods (e.g., Cook and Evans 2000; Card and Rothstein 2007; Vigdor and Ludwig 2008).

After a protracted legal battle beginning in the late 1990s, Charlotte-Mecklenburg school (CMS) district was ordered by the North Carolina State Supreme Court to disband race-based busing. Beginning in fall 2002, CMS switched to a neighborhood-based student choice plan. The key features of the new assignment policy were that school boundaries were redrawn as contiguous areas around a school, and students were assigned to their neighborhood school by default. Because neighborhoods in Charlotte were still highly segregated, this change led to a large and sudden increase in school segregation in the fall of 2002.

In this article, we study the effect of the end of court-ordered desegregation in CMS on students' achievement test scores, educational attainment, and criminal activity. We match college attendance records from the National Student Clearinghouse (NSC) and arrest and incarceration data from the Mecklenburg County Sheriff (MCS) to yearly student records from CMS. These matches are done using full name and date of birth, enabling us to track students who subsequently leave or drop out of CMS. Critically, the CMS data also include students' exact addresses measured in the fall of each school year, which allows us to assign students to neighborhood school zones under the two policy regimes. Furthermore, we use students' addresses measured prior to the policy change to fix their location. This allows us to treat exit from CMS, residential relocation during the prior school 
year, and other related responses as endogenous outcomes of the boundary change.

Our identification strategy compares students who lived in the same neighborhoods but whose prepolicy addresses placed them on opposite sides of a newly drawn school boundary. We estimate the differential effect, within small geographic areas, of being assigned to a school with more minority students. We then examine variation in the effects across student characteristics, grade cohorts, and baseline neighborhood racial composition. The main threat to identification is differential neighborhood trends that are correlated with the location of the boundaries. We show that although minority and low-income students were more likely to be assigned to segregated schools overall, there is no evidence of sorting within neighborhoods across a newly drawn boundary. We also examine the effect of the boundary change on students in older grade cohorts, who should not have been exposed to the policy change. We find no evidence of prepolicy trends in school racial composition.

Our results show that the resegregation of CMS schools widened inequality of outcomes between whites and minorities. We estimate that all students, white and black, score lower on high school exams when they attend schools with more minority students. We find that a 10 percentage point increase in the share of minorities in a student's assigned school decreases high school test scores by about 0.014 standard deviations, which aligns closely with results from other studies of the effect of peer racial composition (e.g., Hoxby 2000; Vigdor and Ludwig 2008; Hanusheket al. 2009). Since the net effect of rezoning was that students attended schools with a greater share of peers of their own race, our estimates imply a widening of the racial achievement gap of about 0.025 standard deviations. We also find that white students are less likely to graduate from high school or attend a four-year college when they are assigned to schools with more minority students.

The rezoning of CMS schools led to large and statistically significant increases in crime among minority males. Our estimates suggest that a 10 percentage point increase in assigned school share minority led to an increase among minority males in the probability of ever being arrested and ever being incarcerated of about 1.5 percentage points, about an $8 \%$ increase relative to the mean for minority males in the sample. The increase in crime is similar in magnitude across grade cohorts and persists 
through the end of our data in 2011, nine years after the rezoning. Moreover, we find that the increases in crime are driven entirely by poor minority males who live in highly segregated neighborhoods and are assigned to schools with higher shares of poor minority students. Overall, the effects on crime align with several other studies of nonlinear peer effects, which find that grouping high-risk youth together increases the aggregate level of misbehavior and/or crime (Cook and Ludwig 2006; Carrell and Hoekstra 2010; Bifulco et al. 2011; Deming 2011; Imberman et al. 2012).

Interestingly, we find that the effect of rezoning on academic outcomes is somewhat greater among older students, who were entering or already enrolled in high school in the fall of 2002 . We present suggestive evidence that increases in resource allocation toward high-minority high schools in CMS may have mitigated the effect of rezoning for younger cohorts. This evidence is consistent with Reber (2010), who finds that the benefits of desegregation were driven by increases in resources rather than exposure to whites, and Lutz (2011), who finds evidence of compensatory resource allocation after the end of court-ordered busing across a broad range of school districts. However, the effects on crime do not diminish over time.

This article provides evidence that school segregation has an important influence on racial inequality in longer run outcomes. Our work is most closely related to Lutz (2011), who uses differential timing of court orders to compare outcomes in districts before and after changes in student assignment plans and finds that dismissal of a court order leads to small increases in the black dropout rate in non-Southern districts. Our results complement Lutz (2011) in several ways. First, the rezoning of CMS schools led to changes in segregation that were considerably larger than the average district in Lutz (2011). The seven-year change in the exposure index (a commonly used measure of segregation) was about 13 percentage points, which is nearly as large as the effect of court-ordered desegregation in the 1960s and 1970s (Rossell and Armor 1996; Guryan 2004). Second, studentlevel data from a single district coupled with a quasi-experimental research design allow us to explore how changes in school racial composition might affect students through different mechanisms such as school resources and peer effects (Reber 2010; Cascio et al. 2010; Johnson 2011; Bifulco et al. 2011; Imberman et al. 2012). Third, we add to the literature on the effect of school 
and neighborhood interventions on long-run outcomes such as college attendance and crime (Katz et al. 2001; Ludwig et al. 2005; Kling et al. 2007; Angrist et al. 2011; Deming 2011; Chetty et al. 2011; Deming et al. 2013; Dobbie and Fryer 2013;).

Do segregated schools inevitably lead to racial and socioeconomic inequality? Or can the consequences of school segregation be mitigated by compensatory allocation of resources? This is a critical question for education policy. Beginning in the early 1990 s, school districts across the United States have been gradually released from court-ordered desegregation plans, and school segregation has increased as a result (Lutz 2011; Reardon et al. 2012). Today, as a result of federal programs such as Title I and a variety of state and local initiatives, racial and socioeconomic gaps in school spending have narrowed considerably and in some cases reversed. Our results provide suggestive evidence that equal or greater resources combined with active policy efforts may be able to reduce the effect of school segregation on academic outcomes, but not crime. To the extent that crime is driven by social context and peer interactions, it will be difficult for schools to address racial and economic inequality through means other than deliberately integrative student assignment policies.

\section{BACKGROUND}

The landmark Supreme Court decision Brown v. Board of Education in 1954 disallowed de jure racial segregation of schools, but the Court's 1971 Swann v. Charlotte-Mecklenburg Schools decision led to the implementation of race-based busing. Although CMS had no explicit race-based assignment policy, the Court ruled schools were de facto segregated, due to highly segregated neighborhoods and contiguous catchment areas around each school. Following the court order, school zones in CMS were redrawn to capture noncontiguous areas with different racial compositions. CMS was mandated to keep each school's percent black within 15 percentage points of the district average, and CMS periodically redrew boundaries to ensure that this balance was kept. Racial balance was preserved using "satellite" zones that bused students from inner-city neighborhoods with high shares of minority students to schools located in suburban, highly white neighborhoods. 
In the early 1990s, the legal status of court-ordered desegregation became tenuous. Since 1990, every contested motion for a school district to be declared unitary has resulted in a dismissal of the desegregation plan (NAACPLegal Defense and Education Fund 2000). Lutz (2011) finds that about $60 \%$ of the original effect on integration is reversed within 10 years after a district is declared unitary, and this change in segregation increases dropout rates and private school attendance among black students outside of the South. In 1997, a CMS parent sued the district because their child was denied entrance to a magnet program based on race (Capacchione $v$. Charlotte-Mecklenburg Schools). This case escalated into a reopening of Swann in 1999 in a series of court battles that ended in April 2002, leaving CMS no choice but to end race-based busing permanently. ${ }^{1}$ The CMS school board discussed alternatives during the 1999 trial and adopted a neighborhood-based school choice plan (the "Family Choice Plan" or FCP) in December 2001.

New school boundaries for the fall of 2002 were drawn as contiguous areas around schools. Families were assigned to their neighborhood school by default, but could apply to attend other schools in the district, including magnet schools. Enrollment was subject to capacity constraints, and schools that were oversubscribed had admission determined by lottery (Hastings et al. 2008; Deming 2011; Deming et al. 2011). To limit school segregation, CMS gave priority in the admissions lotteries to poor students who applied to schools that were majority nonpoor. They also paired the FCP with a program called the Equity Plan, which provided high-poverty schools with additional resources, such as smaller class sizes, bonuses for teachers, and bond funds for renovation (Mickelson et al. 2009).

Under FCP, many of the previous school boundaries were redrawn. Figure I provides an illustration of this change for two middle schools; the top panel shows boundaries for the school year 2001-2 and the bottom panel shows the new boundaries drawn for fall 2002. Not only did satellite zones disappear, but the zones surrounding both schools were redrawn to ensure that

1. In September 1999, the district was ordered to discontinue the use of race in student assignment. The Swann plaintiffs appealed (Belk v. CharlotteMecklenburg Board of Education) and in November 2000 the ruling was overturned, holding that further review was necessary (Mickelson 2003). In September 2001, the declaration of unitary status was affirmed, and a last-ditch appeal to the Supreme Court was denied in April 2002. 


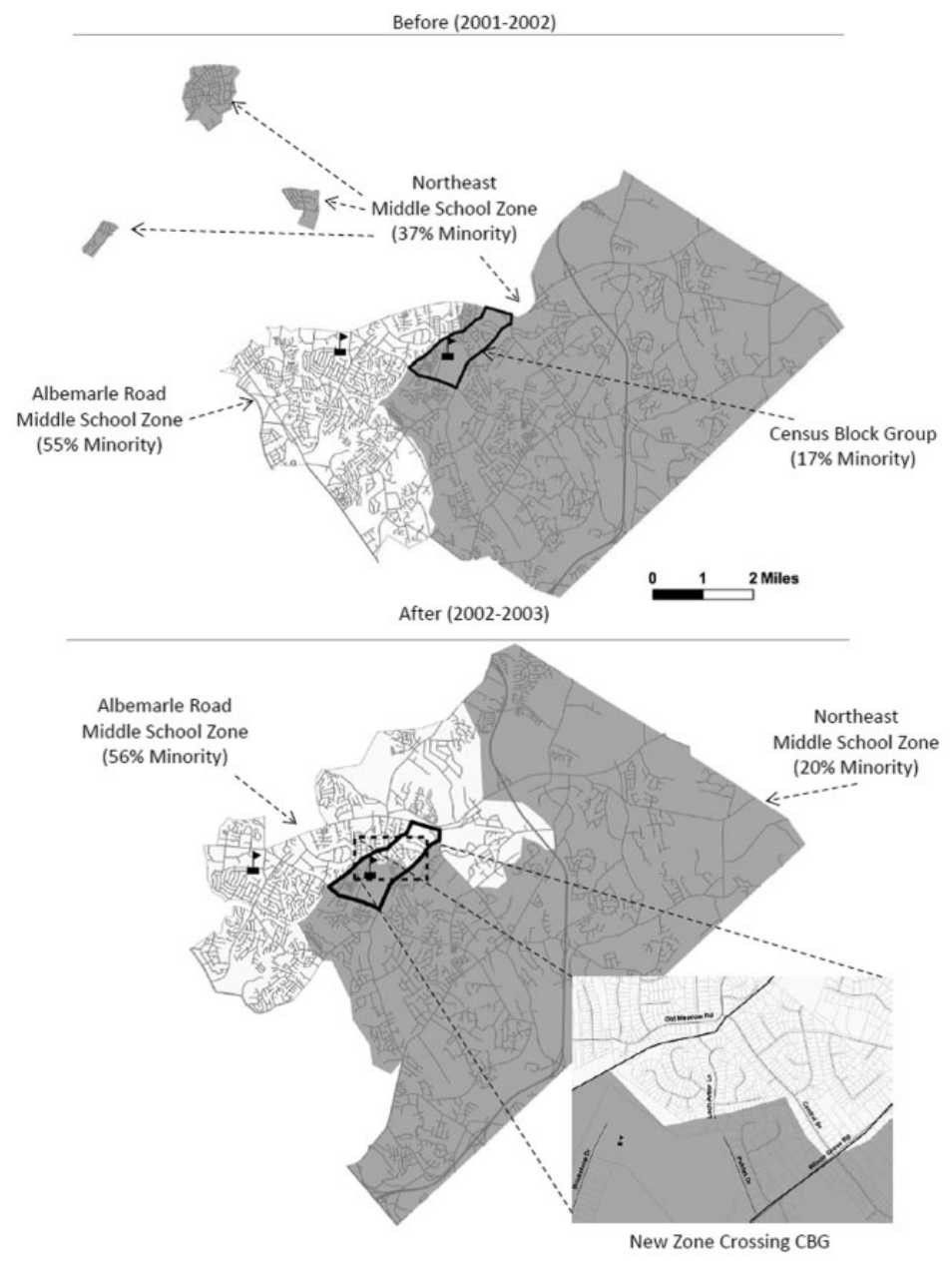

FIGURE I

Rezoning for Two Middle Schools

schools were not overcrowded. Decisions about where to draw the boundaries were governed primarily by enrollment projections, with diversity taking an explicit backseat (Smith 2004; Mickelson et al. 2009). ${ }^{2}$ Whereas many preexisting boundaries took

2. For example, at the November 9, 1999, meeting of the CMS Board, Superintendent Eric Smith described the idea behind the new process, saying, "It's a mechanical process, not a human process. It simply draws [maps] based on 


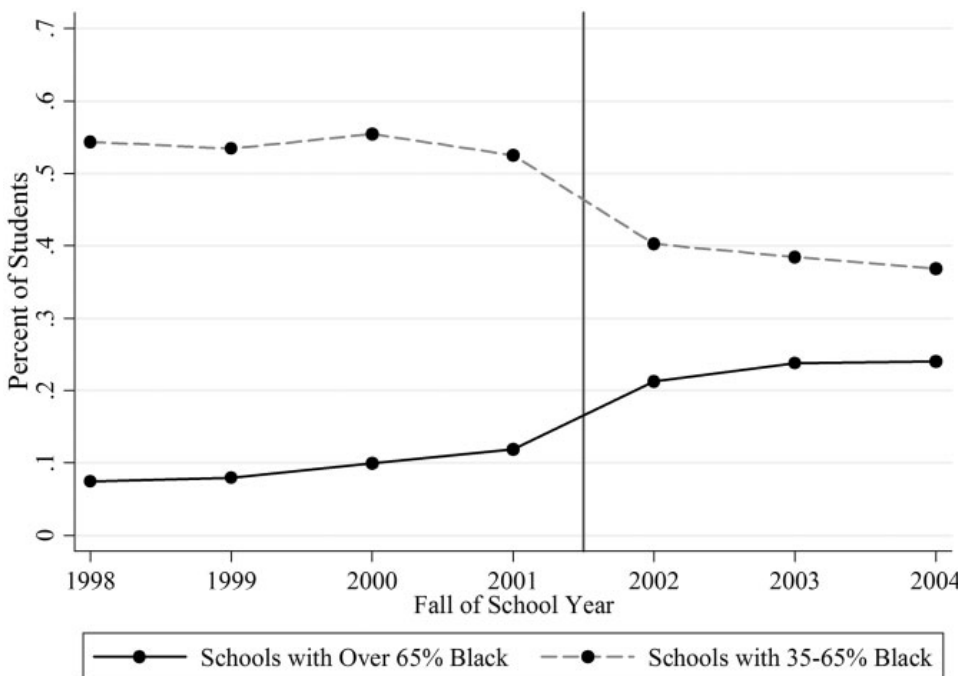

FIGURE II

Effect of the 2002 Rezoning on the Concentration of Black Students

This figure shows the time trend in the share of CMS students in grades 6-12 who were enrolled in schools of varying racial composition. Source: NCES Common Core of Data.

advantage of natural features such as streams or major roads, the newly drawn boundaries were less likely to do so because of the mechanical process that governed rezoning. ${ }^{3}$ The bottom panel of Figure I also shows how the new school zone boundaries were often not coterminous with census block group boundaries, creating variation in school assignments for students living in the same neighborhood. ${ }^{4}$

The redrawing of CMS boundaries as contiguous neighborhood zones led to a marked increase in school segregation between school years 2001-2 and 2002-3. In Figure II, we see

capacity and numbers of children, it doesn't make any sense in terms where children play, associations children naturally make as they are growing up, and it doesn't make any sense in terms of how families relate and interact."

3. Online Appendix Figure A1 shows a kernel density plot of the share of old and new boundaries that abut a natural or manmade feature, and a KolmogorovSmirnov test for equality of distributions yields a $p$-value of .017 .

4. We employ multiple definitions of neighborhood in our analysis, including tax parcel groups, which were also not often coterminous with school boundaries and are considerably smaller than census block groups. 
that the proportion of students attending a middle or high school with a high concentration of black students (over 65\%) jumped from $12 \%$ to $21 \%$, while the proportion attending a relatively integrated school-35-65\% black-fell from 53\% to $40 \%$. We find similar patterns when we examine changes over time in two widely used measures of segregation - the index of dissimilarity and the exposure index (e.g., Massey and Denton 1989). ${ }^{5}$ The change in the exposure index from 2001-2 to 2002-3 was about 5 percentage points. In contrast, Lutz (2011) finds that the termination of court-ordered busing plans beginning in the early 1990s led to virtually no short-run change in the exposure index, and a 10-year change of about 3.5 percentage points. In CMS, the change in the exposure index from 2001-2 to 2008-9 was about 13 percentage points, which is similar in magnitude to the effect of court-ordered desegregation in the 1960s and 1970s (Rossell and Armor 1996; Guryan 2004).

\section{DATA}

We use administrative records from CMS that span kindergarten through 12th grade and the school years 1995-96 through 2010-11. Every student who attended a CMS school for at least one semester is included, and students are tracked longitudinally across years. The data include information on student demographics such as gender, race and eligibility for free or reduced price lunch (our indicator of poverty); yearly end-of-grade (EOG) test scores for grades 3-8 in math and reading; and scores on high school end-of-course (EOC) exams in subjects such as algebra I, geometry, and English. The data also include information on graduation from CMS high schools and transfer records. Our data also include the exact address of residence in every year for every student in CMS, again from 1995 to the present. As we discuss shortly, this allows us to determine each student's

5. Online Appendix Figure A2 presents a time trend from 1998 to 2007 in the dissimilarity and exposure indexes. The index of dissimilarity can be interpreted as the share of students that would have to be moved to different schools to reproduce the overall racial composition of CMS in each individual school. The exposure index calculates the probability that a minority student's randomly drawn schoolmate is also a minority-the minimum value for this measure is the percent minority overall in the district. These measures are calculated using CMS data, whereas the proportion of students attending segregated schools is calculated using the Common Core of Data. 
school assignments under the busing and postbusing regimes. We also incorporate data from CMS's human resource files from 1999 onward, which contain measures of teacher characteristics, including years of experience, salary, and postsecondary credentials.

We match CMS administrative records to a registry of all adult (defined in North Carolina as age 16 and above) arrests and incarcerations in Mecklenburg County from 1998 to $2011 .^{6}$ The MCS tracks arrests and incarcerations across individuals using a unique identifier that is established with fingerprinting. The arrest data include information on the number and nature of charges, and the incarceration data include a time and date of entry and exit, with stints in county jail and state prison both included in length of incarceration for individuals who serve concurrently. Although these data allow us to observe future criminal behavior of CMS students, regardless of whether they transfer or drop out of CMS schools, they are limited to crimes committed within Mecklenburg County.

We use data on college attendance records from the National Student Clearinghouse (NSC), a nonprofit organization that provides degree and enrollment verification for more than 3,300 colleges and $93 \%$ of students nationwide. NSC information is available for every student of college age who had ever attended a CMS school, including students who transfer to other districts or private schools or who drop out of school altogether.

We limit our analysis sample to the seven cohorts who were rising first-time sixth-grade students in the fall semesters of 1996 through 2002. Students who enter CMS after the change in boundaries are not included in the sample. Those who attended 6th grade in the fall of 1996 and progressed through school at the normal rate of one grade a year would enter 12 th grade in the fall of 2002 , and thus would have had only one year of exposure to the change in school boundaries. In contrast, students who attended sixth grade in the fall of 2002 spent all of their middle and high school years in the postbusing regime. Though these seven cohorts span the range of "treated" students, we also examine the

6. We use name and date of birth to link individuals across the two data sources. Although close to $90 \%$ of the matches are exact, we recover additional matches using an algorithm for partial matches that has been used and validated in previous work (Deming 2011). 
effect of rezoning on earlier cohorts in a set of specification checks.

If the youngest cohort of "treated" students had progressed one grade a year, they would have graduated from high school in spring 2009 and could potentially have attended college for the first time in fall 2009. Because our data on college attendance and crime end in 2011, we have limited ability to look at the effect among younger cohorts of students who experienced a change in segregation in elementary school. We also cannot examine longer run measures of educational attainment, such as persistence in college and college degree completion. Thus our main measure of postsecondary attainment will be whether a student attended college within 12 months of the fall after their expected high school graduation date. With this measure, students who repeat a grade but still attend college immediately after graduation can be counted, as can students who delay postsecondary enrollment for up to a year after on-time high school graduation.

We define residential neighborhoods within Mecklenburg County using the 371 block groups from the 2000 Census. We also use data from the County Tax Assessor's Office to define 981 "micro-neighborhoods," which are based on similar real estate parcels (Linden and Rockoff 2008). We use address records from the spring of each school year to assign students to 2000 census geographies, micro-neighborhoods (based on tax parcel), and middle and high school zones for both the pre- and post-2002 boundaries.

Because families may sort in response to the policy change, it would be problematic to use their contemporaneous addresses to assign students to neighborhoods and school zones. Instead, we assign every student to pre- and post-2002 school zones based on their earliest listed address, which is observed in spring 1996 in most cases. We omit a small number of students whose first address is recorded in spring 2002, after the boundary change was announced (but before fall 2002, when the new boundaries applied). This approach minimizes the possibility that sorting will bias our estimates, but it also increases measurement error because some families will have moved to other areas by 2002 . We also omit all students who enter CMS after fall 2002, because of a lack of data on prepolicy addresses. Though this approach minimizes bias, it also means that our results only generalize to the type of family that had some tolerance for race-based busingotherwise they would not have been enrolled in CMS prior to 
2002. We also examine two alternatives for assigning students to neighborhoods and school zones: (1) address in the fall of fifth grade, or (2) address in the latest year observed up to fall 2001. These options trade off the benefits of comparing all students based on residence just before entering middle school but at different points in time versus comparing them based on residence just before the reform but at different grade levels. Although our preferred estimates use the earliest address, the results are very similar regardless of which alternative we choose. ${ }^{7}$

Of our initial sample of 54,093 students, just over $5 \%$ have missing or invalid address information, which leaves us with 51,020 students. We further restrict the sample to the 43,949 students who were previously enrolled in CMS in the academic year 2001-2. ${ }^{8}$ Table I lists descriptive statistics for our sample. Overall, $44 \%$ of students are black, $5 \%$ are Hispanic, and just over half of all students come from poor households (i.e., receiving free or reduced-price lunch). Fifth-grade test scores were slightly higher than the state average in math and reading. Overall, $52 \%$ of students were assigned to a new school as a result of the 2002 change in school zone boundaries.

Splitting the sample by the percentage of minority residents in the student's census block group (CBG) gives a sense of how residential segregation would lead to school segregation under a policy of contiguous neighborhood school zones. We split the sample at $20 \%$ and $66 \%$ minority, which are close to the minimum and maximum share of minority students in any CMS high school under race-based busing. In CBGs with fewer than $20 \%$ minority residents, few students are black (8\%), Hispanic (2\%), or poor (14\%), whereas in CBGs with more than $66 \%$ minority residents the vast majority of students are black (87\%) or Hispanic (5\%) and poor $(89 \%)$. Although it is clear that residential and racial segregation is driven predominantly by the location of black families and students-Hispanics are a small part of the overall

7. Online Appendix Table A1 presents results for the main outcomes of the article when we instead group students by their latest known address up to spring 2001. Online Appendix Table A2 presents identical results when we group students based on their address in fifth grade (students who do not enter CMS until after fifth grade are excluded from the analysis, regardless of grade cohort).

8. Including students who have valid address data but had left CMS prior to 2001-2 attenuates the main results slightly but does not change the statistical significance or the general pattern of our findings. Moreover, using 2002 and 2003 addresses to fill in missing address data has no effect on the main results. 
TABLE I

Sample Descriptive Statistics

\begin{tabular}{|c|c|c|c|c|}
\hline & \multirow[b]{2}{*}{ Full sample } & \multicolumn{3}{|c|}{ CBG percent minority } \\
\hline & & $<20 \%$ & $20-66 \%$ & $>66 \%$ \\
\hline Sample size & 43,949 & 17,931 & 17,989 & 15,100 \\
\hline Black & 0.45 & 0.08 & 0.46 & 0.87 \\
\hline Hispanic & 0.05 & 0.02 & 0.07 & 0.05 \\
\hline Free/reduced lunch & 0.51 & 0.14 & 0.54 & 0.89 \\
\hline 5 th-grade math & 0.03 & 0.56 & -0.03 & -0.56 \\
\hline 5th-grade reading & 0.02 & 0.55 & -0.04 & -0.56 \\
\hline Reassigned & 0.52 & 0.34 & 0.46 & 0.81 \\
\hline Graduated high school & 0.63 & 0.73 & 0.62 & 0.53 \\
\hline Attend 4-year college & 0.38 & 0.56 & 0.34 & 0.21 \\
\hline Ever arrested & 0.10 & 0.04 & 0.09 & 0.17 \\
\hline Ever incarcerated & 0.08 & 0.03 & 0.07 & 0.15 \\
\hline
\end{tabular}

Notes. These descriptive statistics are for first-time, rising sixth-grade students in CMS between fall 1996 and fall 2002 for whom we possess valid address data ( $96 \%$ of enrolled students in these cohorts) and who were enrolled in CMS in the 2001-2 school year. We define "minority" as black and Hispanic students, and "nonminority" as all other ethnicities (including whites). Student eligibility to receive free or reduced-price lunch is an indicator of poverty. Fifth-grade math and reading scores are in standard deviation units and are normed at the state-year level. Reassignment is an indicator for whether a student was assigned to a new school in fall 2002, relative to the previous year. College outcomes are measured using any attendance within the 18-month period after the student would have graduated on time from high school. Crime outcomes are measured beginning at age 16. CBG Percent Minority reflects percentage of residents who are black or Hispanic in the 2000 Census block groups in which student addresses were located.

population and more evenly distributed across geographic areas-the court order (and its removal) was based on the distribution of both black and Hispanic students, and we aggregate the two minority groups in our analysis. Finally, Table I shows that the probability of being reassigned was significant across all neighborhoods (52\%), but students living in high-minority neighborhoods were much more likely to be reassigned $(81 \%)$ relative to those in low-minority neighborhoods (34\%).

CMS currently serves over 135,000 students and is the 18 th largest school district in the nation. Moreover, the district population was growing rapidly over this period, particularly for black and Hispanic students. Within our sample, cohort size grew by $32 \%$ over this period, and the share of minority students grew from roughly $40 \%$ to about $52 \%$. These trends were slightly stronger than those the entire state in overall enrollment growth across cohorts (18\%) and growth in share of minority students (from $31 \%$ to $38 \%$ ). Fifth grade math and reading scores in CMS rose from slightly below to slightly above the state average. 
Overall, CMS is fairly representative of large, urban school districts in the Southern United States.

\section{EMPIRICAL STRATEGY}

Our strategy uses student addresses measured prior to the policy change to generate quasi-experimental variation in exposure to schools of varying racial composition. Figure III shows kernel density plots (weighted by enrollment) of racial composition before and after the fall of 2002 for actual school enrollment (top panel) and school assignment based on earliest known address (bottom panel). Prior to rezoning, most students were assigned to and attended a school where the percentage of minority students ranged between $35 \%$ and $65 \%$. In the fall of 2002, these distributions show a marked shift in mass from within the $35-65 \%$ range to the more extreme parts of the distribution, consistent with the time variation shown in Figure II. It is also interesting to note that in line with the presence of magnet programs and alternative schools, the actual distribution of school racial composition was noticeably more disperse than the assigned distribution both before and after rezoning. As Figure III shows, segregation increased markedly in CMS schools in the school year 2002-3.

The rezoning of CMS schools in 2002 meant that students who lived in the same neighborhoods but on opposite sides of a newly drawn boundary could be assigned to schools of very different racial compositions. In an extreme case, students living on opposite sides of a street could be assigned to different schools. Although the broad trend of increasing school segregation was predictable based on the court order, it is unlikely that families could anticipate the location of the boundary within a small neighborhood many years in advance. Our empirical approach formalizes this intuition by regressing outcomes of interest on the percent minority in a student's new school zone (based on the prepolicy change address) while controlling for old school zone by neighborhood fixed effects. We estimate:

$$
Y_{i z j c}=\beta_{0} \text { PctMinority }_{i z j c}+\beta_{1} X_{i z j c}+\eta_{z j}+\gamma_{c}+\varepsilon_{i z j c},
$$

where outcome $Y$ for a student $i$ living in old school zone $z$, neighborhood $j$ and grade cohort $c$, is regressed on the student's new school-zone percent minority (PctMinority $y_{i z j c}$ ), a set of covariates 

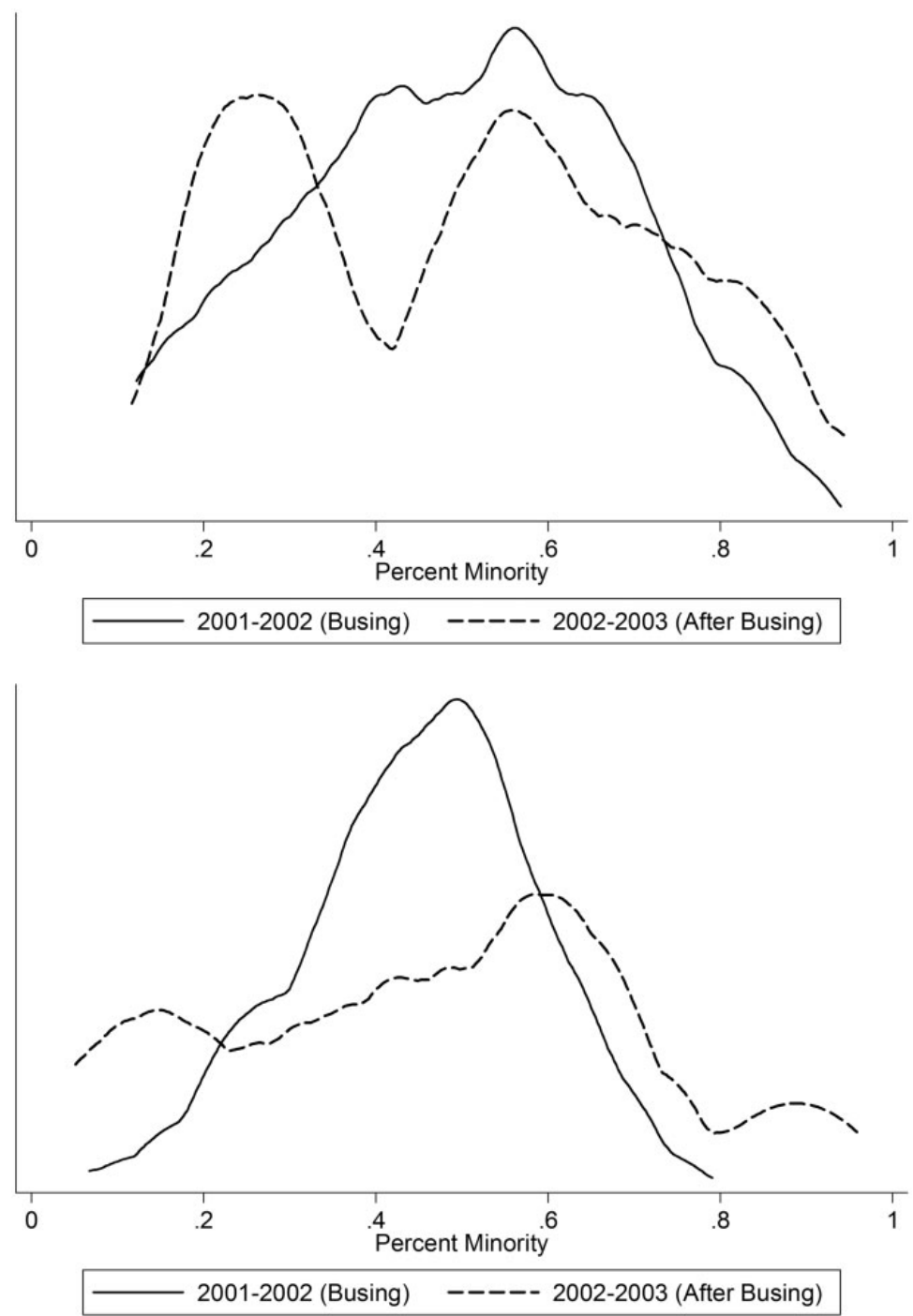

FiguRE III

Density of Middle/High School Racial Composition (Enrollment Weighted) Actual School Attended

The top panel shows kernel density plots of the distribution of the racial composition of the schools attended by students in the sample in the years immediately before and immediately after the rezoning. The bottom panel shows the same thing, except for assigned school. Differences in assigned and actual school occur because of magnet schools, schools for children with special needs, and the Family Choice Plan that was implemented in the 2002-3 year. 
that includes race, gender, free lunch status, and a second-order polynomial in fifth-grade math and reading scores, cohort fixed effects based on the first year a student enters the sixth grade $\left(\gamma_{c}\right)$, and old school zone by neighborhood fixed effects $\left(\eta_{z j}\right)$. We also interact the cohort fixed effects with indicators for eight demographic groups (race by gender by free lunch status) in some specifications to account for time trends in the overall demographic composition of CMS. We cluster the standard errors at both the prior school zone and new school zone by parcel group levels, using the multiway clustering procedure in Cameron et al. (2011).

With old school zone by neighborhood fixed effects $\left(\eta_{z j}\right)$, the coefficient on PctMinority izjc $_{c}$ captures changes in school racial composition for students who live on opposite sides of a newly drawn boundary. In neighborhoods where there is no new boundary, PctMinority $i_{i z j c}$ will have the same value for all students and thus will not contribute to the estimation of $\beta_{0}$. We define neighborhoods in two ways. First, we use CBGs, which are the smallest geographic area for which demographic information is released by the Census Bureau. Our second neighborhood definition is the micro-neighborhood parcel group, previously mentioned, which is used for property tax assessment. Even with these small spatial definitions of neighborhood, $56 \%$ of micro-neighborhoods in CMS had a new boundary drawn through them. The median number of students per micro-neighborhood across our eight sample cohorts is 142 . For increasingly small definitions of a neighborhood, our approach converges to a boundary discontinuity design as in Black (1999) and Bayer et al. (2007), with the important difference that we examine newly drawn boundaries using addresses measured prior to the redrawing. We use parcel groups in our main results, but in general our results are very similar with the two different neighborhood definitions.

Though our approach considers the "treatment" to be a change in school racial composition, PctMinority $i z j c$ is in fact just one of many possible ways we could have defined the meaning of the change in school boundaries. Our approach creates groups of students who lived in the same neighborhoods and were formerly zoned to the same schools. After the boundary change, some of these students received a new school assignment, and some did not. One possible approach would be to replace PctMinority $y_{i z j c}$ with an indicator variable for receiving a new school assignment. This would compare students who switched schools to students who did not. However, boundary changes in 
other neighborhoods bring new peer groups into schools, even if a student's own assignment does not change. In a sense, nearly every student is "treated" by the policy. We have chosen to take a particular stand on the nature of the "treatment"-namely, that it can be measured by PctMinority ${ }_{i z j c}$ - because the policy change represented the end of race-based busing. As we show later, other ways of defining changes in peers (income, prior test scores) are equally valid. In that sense, we are estimating the effect of changes in school racial composition and everything that is correlated with it. Redrawing CMS school boundaries led to rich variation in the racial composition of students' assigned schools. While students were overall more likely to be assigned to schools with peers of their own race, a significant share of nonminority students were reassigned to schools with higher minority enrollment, and a significant share of minority students were reassigned to schools with lower minority enrollment. ${ }^{9}$

Our main results focus on the reduced-form effect of being assigned to a new school. An alternative approach is to use assigned school racial composition as an instrument for actual school racial composition as part of a two-stage least squares (2SLS) procedure. We pursue the reduced-form approach for two reasons. First, we must account for differential exposure by grade cohort to the new school zone boundaries, and any choice of scaling involves strong assumptions about the nature of the treatment. For example, we could estimate the effect of cumulative exposure by multiplying students' percent minority in the new school zone by the number of years they were enrolled after the policy change. However, this assumes that the effect accumulates linearly and is the same for all age groups. Second, there is the difficult issue of how to treat students who leave CMS, since we do not know the racial composition of their new school (or if they are attending any school). If students who attend highly segregated schools are more likely to drop out, then a cumulative scaling would not be appropriate.

We present results with all grade cohorts pooled together, as well as separated out by "middle school" and "high school"

9. Moreover, there is considerable variation even within neighborhoods-the mean interquartile range within parcel groups with variation in the change in percent minority is about 10 percentage points for the middle school boundaries and 7 percentage points for high school. Online Appendix Figure A3 shows the distribution of the change in the percent of minority students between each student's new and old school zone, separately by race. 
cohorts. Students who were entering grades $6-8$ and grades $9-12$ in fall 2002 are in the "middle school" and "high school" cohorts, respectively. We also investigate the sensitivity of our results to a wide array of alternative specifications, such as nonlinear effects of changes in peers and different measures of school composition.

\section{IV.A. Checks on Nonrandom Sorting and Attrition}

The key concern with our approach is that student characteristics are systematically correlated with being on a particular side of a newly drawn school boundary, even within small geographic areas. If true, this would confound our estimates of the effect of being zoned to a school with more minority students. While we cannot measure the influence of unobserved student characteristics, we can test whether students' observed characteristics such as race, income, and test scores are systematically correlated with our independent variable of interest. To test this, we estimate a regression like equation (1), except with PctMinority $_{i z j c}$ as the outcome variable and demographics and prior test scores as the key independent variables, along with cohort and old zone by parcel group fixed effects. We then conduct an $F$-test for the joint hypothesis that all the covariates are equal to 0 . None of the coefficients are individually statistically significant, and we fail to reject this hypothesis in the full sample and then in separate specifications for the high school and middle school cohorts. These results, in Online Appendix Table A3, show that students in the same neighborhoods but with different values of PctMinority izjc $_{\text {c }}$ after the rezoning have very similar characteristics. Despite the apparent balance on prior student characteristics, we still control for them in our main specifications.

Another potential concern for our analysis is incomplete ex post observation of students in our sample, that is, attrition bias. This is particularly relevant for short-run outcomes, like exam scores, which only are available for students who continue to be enrolled in CMS. ${ }^{10}$ In Online Appendix Table A4 we show that the effect of the rezoning on short-run attrition is very small and only statistically significant in some specifications. ${ }^{11}$ Importantly,

10. Overall, $4.3 \%$ of nonminority students and $3.3 \%$ of minority students in our analysis sample were no longer enrolled in CMS in fall 2002.

11. We estimate equation (1), with an indicator variable for being enrolled in CMS in fall 2002 as the outcome. We find that the probability of staying in CMS the 
attrition from CMS is not a concern for our analysis of crime and college-going, which are measured outside of CMS data. Rather, the main concern in these analyses is whether the new student assignment policy is correlated with students' future criminal activity outside of Mecklenburg County or attendance at one of the few colleges not covered by the NSC. We find no evidence to suggest that nonrandom attrition from these data sources is problematic for our results. ${ }^{12}$

\section{IV.B. Impact of Rezoning on Enrollment}

Another possible concern is that the location of the new school boundaries was chosen based on preexisting trends in neighborhood racial composition. In this scenario, the effect of being reassigned would be a smooth trend line that shows up in prior cohorts. We examine this possibility by estimating a series of "first-stage" regressions, with (attended) school percent minority as the outcome, separately by grade and year. Concretely, we measure the effect of being reassigned in fall 2002 on the racial composition of grade cohorts from fall 1995 to fall 2006, using students' earliest addresses in all cases. In Figure IV we present estimates from versions of equation (1), with each point representing an estimate of $\beta_{0}$ and its associated $95 \%$ confidence intervals, for a particular grade and year combination. Overall, we see no evidence of pretrends in the percent minority of students' attended schools in relation to the new school assignments. The confidence intervals for almost all grade cohorts prior to fall 2002 include zero, and there are no obvious trends or differences across grades. Consistent with our identification strategy, we see a steep and discontinuous spike in school percent minority beginning in fall 2002 and persisting for the next five cohorts. The size of this "first-stage" coefficient ranges from 0.2 to 0.3 , indicating that a 10 percentage point increase in assigned school percent minority leads to about a 2.5 percentage point increase in

following year rises by about .002 for students assigned to a school with 10 percentage points more minority students. In Panel B (column (2)), we see that this small increase is concentrated among minorities, though estimated effects of a $10 \%$ increase in minority enrollment at the assigned school are always below 0.01 .

12. Though we cannot test for this type of nonrandom selection directly, the fact that we find very small increases in initial attrition from CMS related to the rezoning helps support the notion that data limitations do not drive our results. The interpretation of later attrition is complicated by the fact that some students who leave CMS may actually be dropping out of school altogether. 
Impact of Rezoning on School Racial Composition

by Grade and Year
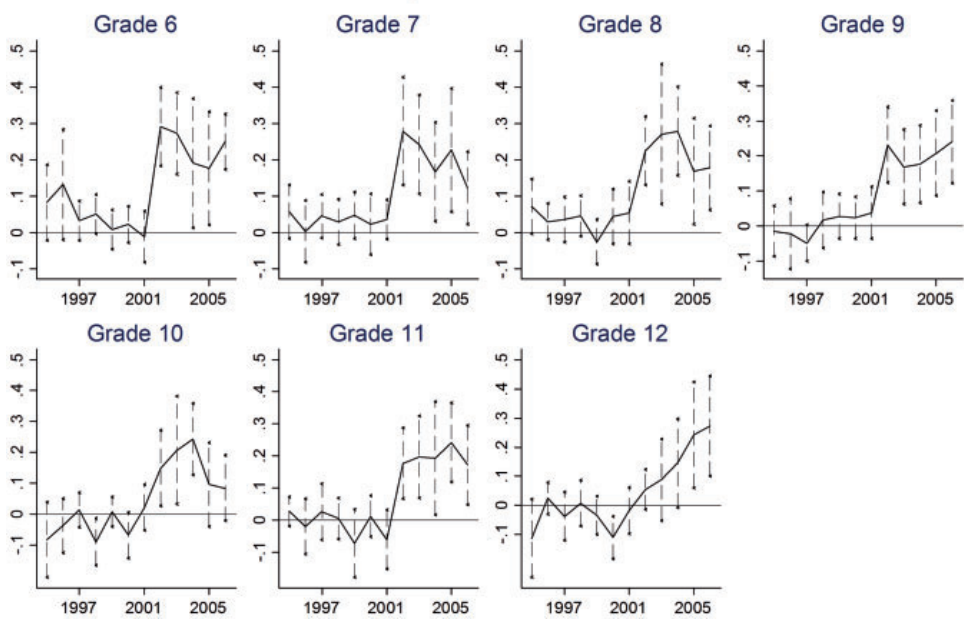

Effect of Rezoning on School Racial Composition by Grade and Year

Each point is the key coefficient and associated 95\% confidence interval from a regression like equation (1), estimated separately by grade and year, and is interpreted as the effect of a 100 percentage point increase in the share minority of a student's assigned school on the share minority of the school the student actually attended in fall 2002. Thus, coefficients for years prior to 2002 act as a check for prepolicy trends in school racial composition.

attended school percent minority. The one exception is 12 th grade, where we see a much smaller estimate in fall 2002 that gradually increases for later cohorts. This is most likely due to the explicit priority that rising 12th-grade students were given in the FCP discussed earlier, combined with a reluctance of students to change schools in their last year of high school.

While the estimates are relatively precise, a coefficient of less than 1 does suggest imperfect compliance with the newly drawn boundaries. Noncompliance can happen for three reasons. First, the use of earliest known address minimizes potential bias from student sorting, and also induces some measurement error because families may no longer live in the same residence by 2002. Second, the FCP allowed for families to choose schools other than the ones to which they were assigned, including magnet schools (which have no neighborhood zone). As noted by Kane et al. (2005), CMS made every effort to accommodate 
choices in the first year, in part by expanding capacity at schools where they anticipated high demand. Third, noncompliance by individual students has an indirect effect because it alters the racial composition of the school for other students. For example, if whites are more likely than minorities within the same school zone to opt out and attend a magnet school, then the first-stage coefficient for compliers will still be less than one because the school is not as "white" as it would have been with perfect compliance.

Table II presents results for a variety of first stage outcomes. Panel A shows results from estimates of equation (1) with percent minority in a student's fall 2002 school as the outcome. In Panel $\mathrm{B}$, which allows the effect of assignment to vary by race, we see that the effect is a bit stronger for whites. The focus on the percent minority students as a policy outcome is motivated by our study of the elimination of race-based busing. Minority students tend to be poorer, have lower academic achievement, and have more disciplinary problems than nonminorities, and the policy changes we study will affect the composition of schools along these dimensions as well. To illustrate, columns (2) and (3) of Table II show that a 10 percentage point increase in the share of minority students in the school zone also leads to having peers that are about 2 percentage points more likely to be eligible for free lunches and who scored about 0.03 standard deviations lower on the fifth-grade math exam. Thus the "first-stage" results are very similar across measures of peer race, income and prior test scores. In Online Appendix Tables A5-A7 we show that we can obtain very similar main results when we replace PctMinority izjc $_{\text {c }}$ with these other measures of school composition. As in other studies of the effect of racial segregation on schools (e.g., Guryan 2004; Jackson 2009; Lutz 2011), our research design cannot separate the effect of race from other factors with which it is correlated, and our results should be interpreted with this in mind. Nevertheless, most efforts to desegregate schools have focused on ethnic and racial composition and have relied on manipulation of school boundaries, so our empirical strategy is well suited to answering a question of great policy interest.

A key point of interpretation is that our results are driven by students who comply with school zone assignments. ${ }^{13}$ Even

13. About $73 \%$ of nonminority students and $55 \%$ of minorities attended their assigned school, $9 \%$ of nonminorities and minorities attended their previously 


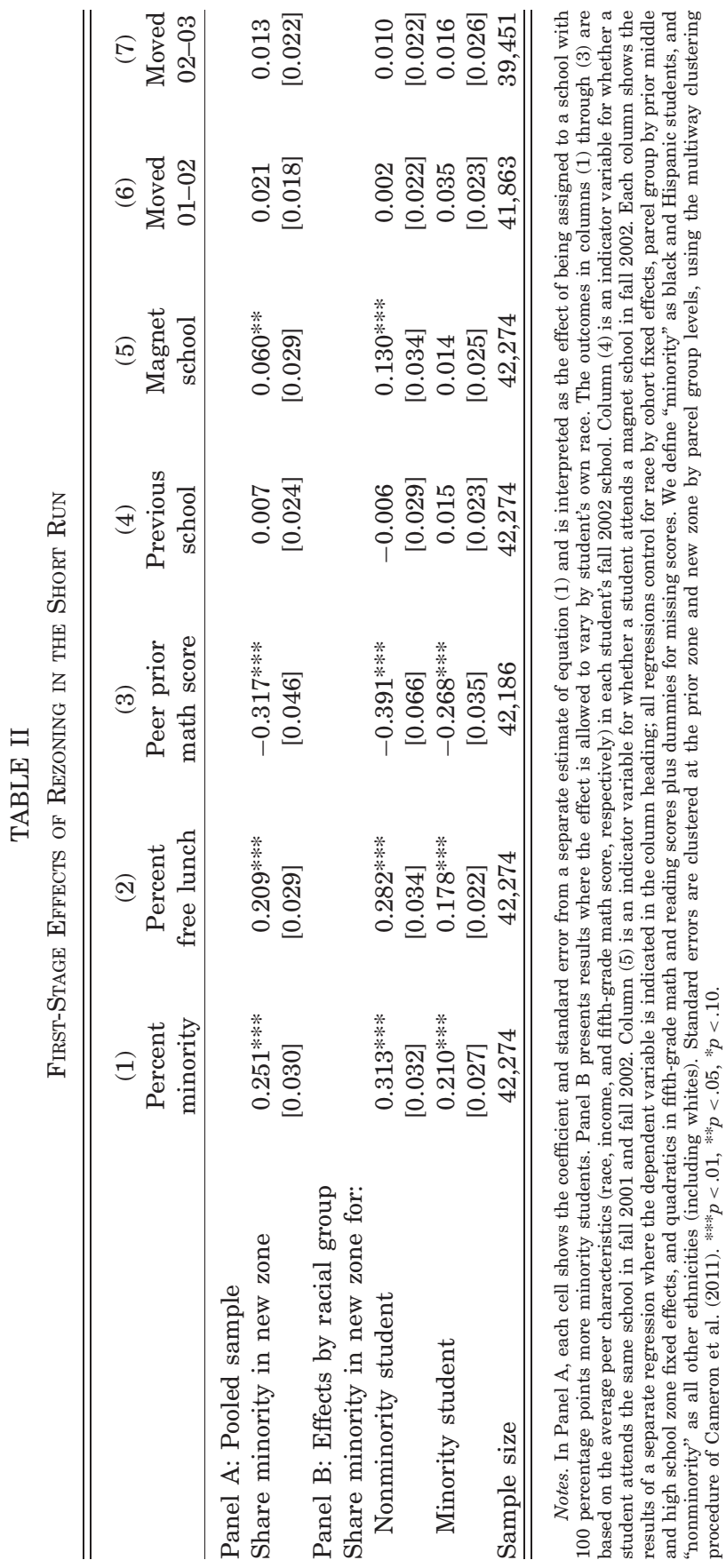


before the policy change and the implementation of the FCP, only about $65 \%$ of students attended their assigned school, mostly because of the existence of magnet programs and alternative schools. This dropped to about $57 \%$ in $2002-3$, and gradually rose back up to about $65 \%$ by $2005-6 .{ }^{14}$ We find little evidence of differential attendance by school type across the newly drawn boundaries, save a statistically significant increase in the probability of attending a magnet program that is concentrated among nonminorities (column (5)). To the extent that magnet schools are academically better than a student's assigned school, this will make the results for whites look more favorable than if we had perfect compliance. Finally, rezoning may have also affected families' decisions to change residence within CMS. In columns (6) and (7), we examine moves between two consecutive school years, from 2001-2 to 2002-3 (the first year of the new student assignment plan), and find no evidence of differences in residential relocation in the years leading up to the policy change.

\section{MAIN RESULTS}

Table III contains the main results of the article. Panel A presents results that pool all students. Panels B and C allow the effects to vary by race and race and gender, respectively. The outcome in column (1) is the average of (standardized) scores on high school EOC exams in four separate subjects. ${ }^{15}$ We find a statistically significant decrease in high school test scores of about 0.014 standard deviations for a 10 percentage point increase in share minority. The impacts are slightly larger for nonminorities, but none of the effects by race or gender are significantly different from each other. In other studies in this literature, an increase of about 10 percentage points in share

assigned school, 9\% of nonminorities and $13 \%$ of minorities attended magnet schools, and the remaining students chose another CMS school.

14. Online Appendix Table A8 shows the share of students attending their home school by grade cohort and year.

15. The four high school test subjects are English I, algebra I, geometry, and algebra II. We average across them to maximize statistical power, and there is no strong pattern of effects by subject. See Online Appendix Table A9 for separate results by test subject. In cases where a student took the exam multiple times, we only use the score from the first exam. When students are missing one or more scores, we simply take the average over the available scores. 


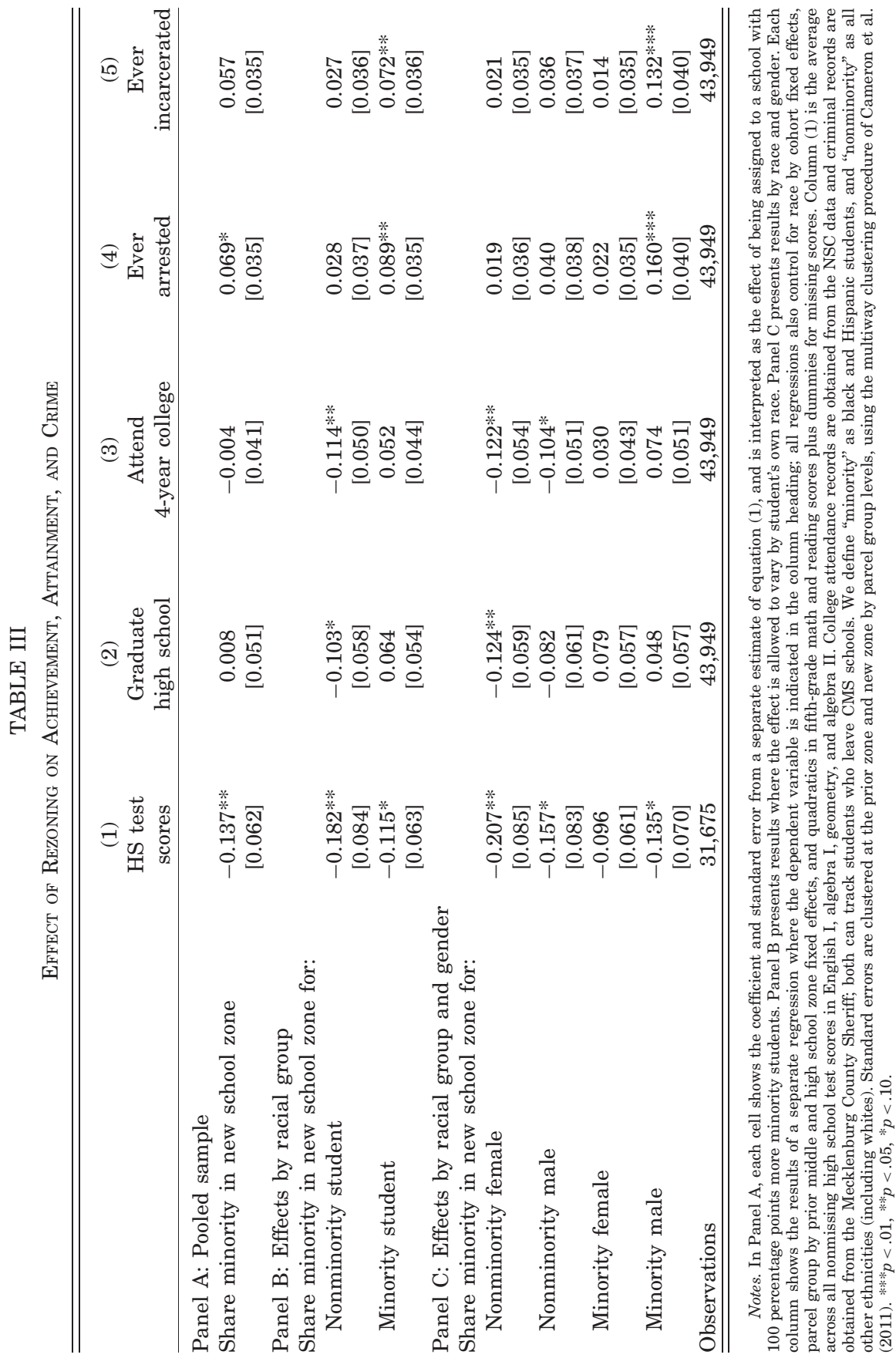


minority has been found to translate to a decrease in math scores of between 0.04 and 0.07 standard deviations (e.g., Hoxby 2000; Vigdor and Ludwig 2008; Hanushek et al. 2009). Although we cannot make a direct comparison given differences in methodology, scaling our reduced-form coefficient of 0.014 by the "firststage" estimate from Table II (0.25) suggests that our estimates are very much in line with this earlier work.

Although there is some variation across students in the timing of the test, controlling for the grade in which the exams are taken has little effect on our estimates, suggesting that timing was not sensitive to the rezoning. Selection into high school test taking is a more serious concern, because advanced math tests are not required for graduation and some students may drop out of high school or leave CMS prior to when they would have taken the exam. We test the robustness of our results by probing their sensitivity to different imputation procedures for missing test scores. The results of these imputations, contained in Online Appendix Table A10, indicate that missing values are not driving our results.

Columns (2) and (3) present results for educational attainment. The results in Panel A show no overall impact of rezoning on high school graduation or four-year college attendance. However, we find large and statistically significant decreases in attainment for nonminority students. The estimates imply that an increase of 10 percentage points in share minority of assigned school leads to a reduction of just over 1 percentage point in both high school graduation and four-year college attendance. In contrast, we find a small increase in attainment for minority students, although the results are not significantly different from zero. We can strongly reject equality of the estimates by race $(p<.001)$. However, the attainment results are not significantly different by gender. When we estimate results for the high school cohorts separately by poverty status (not shown), we find that most of the effect on high school graduation is driven by poor nonminorities (where poverty is proxied by eligibility for free or reduced-price lunches), whereas most of the effect on college attendance occurs among nonpoor students.

Columns (4) and (5) present results for adult crime. The outcomes are indicators for whether a student has ever been arrested in Mecklenburg County and ever been incarcerated in county jail or state prison, respectively. We find that students who are assigned to a school with 10 percentage points more minority 
students are about 0.7 percentage points more likely to have ever been arrested and 0.6 percentage points more likely to have ever been incarcerated. The effect on arrests is statistically significant at the $10 \%$ level. In Panel B, we see that the effects for both crime outcomes are significantly greater for minority students $(p=.002$ and $p=.015$ ). Panel $\mathrm{C}$ shows further that the increases in crime are driven almost entirely by minority males, who are 1.6 percentage points more likely to be arrested and 1.3 percentage points more likely to be incarcerated for a 10 percentage point increase in share minority of assigned school.

Students who move outside of Mecklenburg County (perhaps by attending an out-of-town college) could in principle commit crimes that are not recorded in our data. However, the results for criminal outcomes are nearly identical when we restrict our analysis to students with no college record or when we eliminate students who attend college outside Mecklenburg County. We can also investigate the pattern of results over time by breaking the arrest data into four-month windows. This acts as an additional robustness check, because being rezoned in 2002 should not affect crime prior to the announcement of the policy change. The results, in Online Appendix Figure A4, show a statistically significant increase in arrests that begins around the time of rezoning and persists at roughly the same level for nine years, through the end of our data in 2011, when the age of students in our sample ranges roughly from 19 to 25. Online Appendix Table A11 contains results for additional outcomes such as selective college attendance and total number of arrests.

After the rezoning of CMS schools, students attended schools with a greater share of peers of their own race. Thus we can project the effect of our results on racial inequality in outcomes. In Table III, we show estimated test score decreases for students of all racial backgrounds when they attend schools with more minority students. Since the rezoning led to a decrease in the share of minority peers for white students and an increase for minority students, the net effect was a widening of racial inequality in test scores. To get a sense of the magnitude, we multiply the point estimates from Table III by the mean change in the assigned share minority before and after the rezoning, separately by race. This calculation implies that the rezoning widened the racial gap in high school math scores by about 0.025 standard deviations. However, because of the opposite signs on the coefficients for high school graduation and college attendance, we find 
only a very small change in the racial gap in educational attainment (about 0.3 percentage point). The effects on crime imply that the racial gap in arrest and incarceration rates widened by about 1 percentage point, and nearly 2 percentage points for males.

\section{V.A. Variation in Effects by Grade Cohort}

In Table IV we allow the effect of rezoning to vary by grade cohort. Some students were already most of the way through high school when busing ended, whereas others attended most of middle school and high school in more segregated schools. Examining variation in effects across grade cohorts yields insight into the mechanisms underlying our results-for example, if the impact of school segregation is cumulative, we might expect to find larger effects for younger grade cohorts. We estimate equation (1) for each of the main outcomes of the article, adding an interaction between PctMinority ${ }_{i z j c}$ and an indicator variable for whether a student is in the younger "middle school" cohorts, that is, entering grades $6-8$ in fall 2002. In this setup, the main effect gives the effect for students in the "high school" cohorts-grades 9-12 in fall 2002, and the $p$-value on the interaction is a test for significant differences by grade cohort. We divide the sample into these two groups for ease of presentation-Online Appendix Table A12 shows results that are estimated separately for each grade cohort.

In column (1) of Table IV, we see that a 10 percentage point increase in share minority of assigned school leads to a decrease of about 0.020 standard deviation for students in the high school cohorts, but the interaction term is positive, implying a decrease of only about 0.013 standard deviation in the middle school cohorts. This difference is marginally insignificant at conventional levels $(p=.108)$. In column (2), we also see a small, positive, and statistically insignificant interaction term for high school graduation. In column (3), we find a large difference in the effect on four-year college attendance. A 10 percentage point increase in share minority of assigned school leads to a decline in college attendance of about 0.6 percentage point for the high school cohorts, but an increase of about 0.5 percentage point in the middle school cohorts. The interaction term is statistically significant at the less than $1 \%$ level. However, in columns (4) and (5) we find no significant difference across cohorts for crime outcomes. The bottom half of Table IV allows these effects to vary further by 


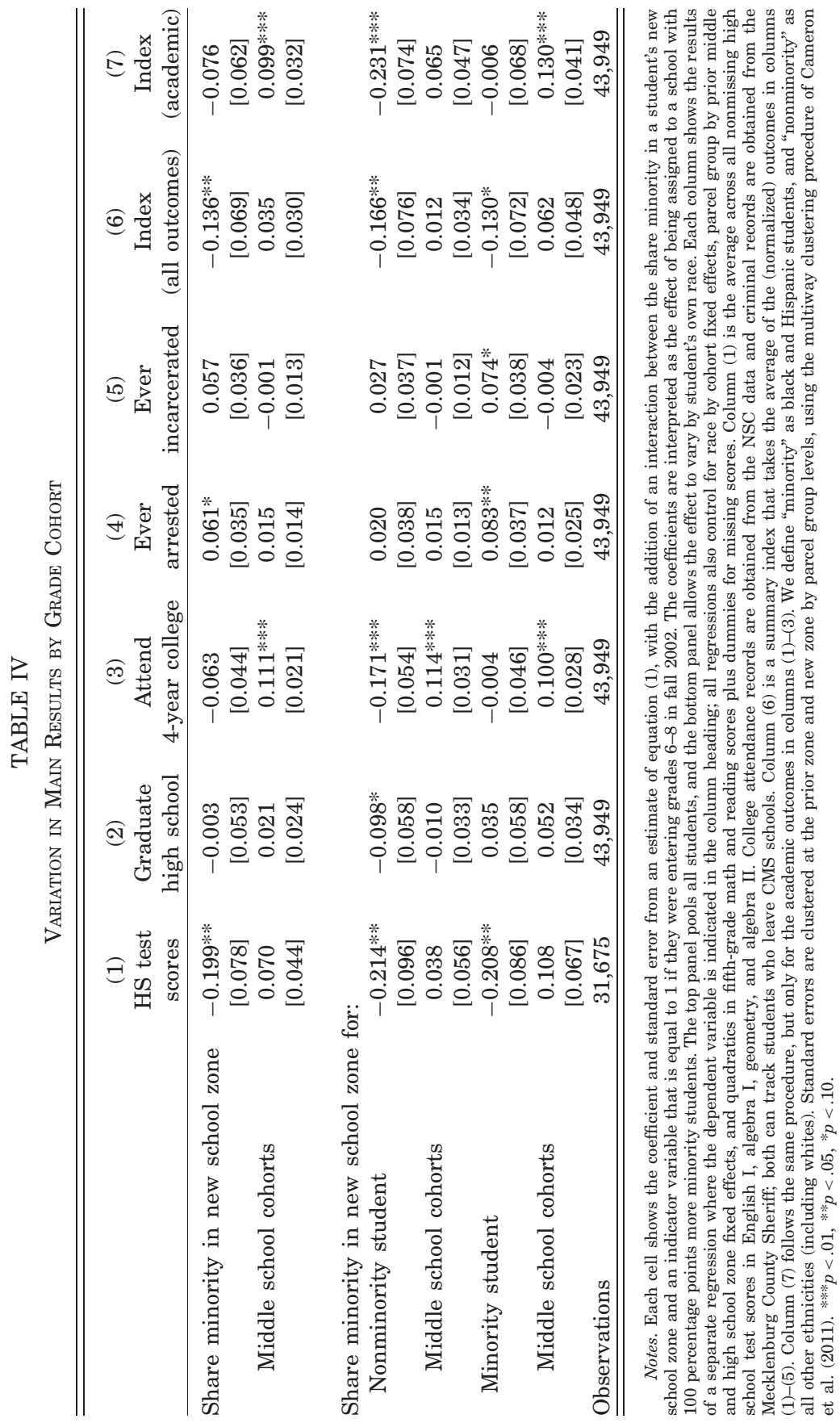


students' own race. The pattern of results is very similar to the pooled specification.

To test for the overall significance of this pattern, we generate a summary index that (1) normalizes all five outcomes to have mean 0 and standard deviation 1; (2) reverses sign for the crime outcomes so that positive values are "good"; and (3) takes the simple average across the five outcomes, or four of five when high school test scores are missing. We also create a similar index that averages across the three academic (i.e., noncrime) outcomes. The results are in columns (6) and (7). We find that attending a school with 10 percentage points more minority students leads to a decline of about 0.014 standard deviation in outcomes for students in the high school cohorts, and about 0.010 standard deviation in the middle school cohorts. The difference is not statistically significant. However, we do find a highly significant $(p=.002)$ difference of about 0.010 standard deviation across cohorts for the three academic outcomes, driven mostly by fouryear college attendance. The difference is larger (about 0.013 standard deviation) for minority students. From this we conclude that the impact of rezoning on racial inequality was modestly larger for students in the older grade cohorts, particularly for academic outcomes and for racial minorities. The next section explores possible reasons for this pattern of results.

\section{DISCUSSION}

We consider four possible explanations for the pattern of results. The first is that the effect of rezoning comes not through changes in the school itself but from endogenous reactions, such as families exiting CMS for private school or moving to a different neighborhood to attend another public school. We examine the effect of endogenous mobility in a variety of ways and find no evidence that this is an important contributor to our results. ${ }^{16}$

The second possible explanation is that students may be harmed by additional school transitions. In this scenario, it is

16. In Online Appendix Table A13 we reestimate our main results for crime and college attendance while excluding the approximately $4 \%$ of students who were not enrolled in CMS in fall 2002. In Online Appendix Table A14 we exclude the approximately $14 \%$ of students who relocated to a new address between fall 2001 and fall 2002. In Online Appendix Table A15 we estimate the effect of rezoning on attrition from CMS over time. 
not the racial composition of the school that matters but simply being rezoned to any new school. We test this explanation in three ways. First, in Online Appendix Table A12 we analyze results separately by cohort to see if the impacts are smaller for rising 6th- and 9th-grade cohorts, when most students are attending a new school anyway. Second, in Online Appendix Table A16 we restrict the sample only to students who received a new school assignment, to see if there is a similar gradient in outcomes by peer characteristics once we eliminate students who kept the same school assignment. In both cases, we find no evidence that the results are driven by additional school transitions. A third related hypothesis is that the increase in crime among minority males is explained by the end of the long bus rides that often characterize school desegregation plans. We test for this possibility in Online Appendix Table A17 by excluding the approximately $4.5 \%$ of students who attended noncontiguous school zones prior to the policy change (the "bused" children), but it has very little effect on our results.

\section{VI.A. Changes in Resource Allocation}

A third possible explanation for the results is that the end of race-based busing shifted the allocation of resources across CMS schools. Recent work on the effect of court-ordered school desegregation in the 1960s and 1970s shows that racial integration was also accompanied by a narrowing of racial gaps in per-pupil spending and class size (Cascioet al. 2010; Reber 2010; Johnson 2011). This suggests that increased resources, beyond changes in school racial composition itself, may have been an important mechanism for improvements in the outcomes of black students during this period (e.g., Margo 1990; Card and Krueger 1992).

Did the resegregation of CMS schools widen racial gaps in resources? Jackson (2009) shows that teachers, who are the main factor in school expenditures, sorted across schools in response to the policy change-he finds that a 10 percentage point increase in the share of black students leads to a reduction in elementary school teacher value-added of about 0.01 to 0.02 teacher-level standard deviation. Those results show that resources shifted away from schools that received inflows of poor and minority students. However, the results in Jackson (2009) only 
apply to the first year of the rezoning and are not focused on high schools.

We investigate changes in school resources over time using a detailed database of CMS teacher and staff characteristics. Although we were unable to obtain disaggregated spending data for the years prior to rezoning, the personnel data (which includes teacher salaries) go back to 1999. This enables us to calculate per-pupil spending on teacher salaries, which is the most important contributor to school spending (and nearly all of spending on instruction). We can also investigate changes across schools and over time in teacher characteristics such as education and experience.

To address equity concerns and perhaps in anticipation of teacher sorting, CMS paired the new student assignment policy with a program called the Equity Plan, which provided additional funds to high poverty schools for recruitment bonuses for teachers, lower student-teacher ratios, school renovation projects, learning equipment, and supplies (Mickelson et al. 2009). However, budget cuts limited the effect of the Equity Plan in the first years after rezoning (Mickelson et al. 2009). In 2006, CMS began a program called the High School Challenge, which targeted the four high schools with the highest shares of poor and minority students. The High School Challenge was created as a response to the schools' inability to meet state accountability benchmarks for achievement on EOC tests and was funded by the Mecklenburg Board of County Commissioners and the federal Teacher Incentive Fund (CMS Schools 2005). The program increased teacher salaries in these schools by $15 \%$ and offered signing bonuses of up to $\$ 15,000$, but also increased accountability, allowing for expedited removal of teachers and principals as well as restructuring of schools that were not meeting performance standards (CMS Schools 2008). By 2008, the High School Challenge schools had increased their performance on a composite of EOC tests by an average of 12 percentile ranks. The one school that did not make substantial gains (Garinger High School, which moved from $41 \%$ to $43 \%$ from 2005 to 2008) was reconstituted as five small "academy" programs with themes such as technology, business and finance, and international studies.

Teacher salary data confirm the narrative above. Per-pupil spending on teacher salaries was close to uniform across schools prior to rezoning, become modestly more variable in $2002-3$, and 
then diverged further in 2006-7 when the High School Challenge program was implemented. ${ }^{17}$ Beginning in 2006-7, the four targeted high schools spent about $20 \%$ more per pupil (not including capital costs) than the average CMS high school. More generally, the relationship between the share of minority students in a CMS high school and two measures of resources (per-pupil spending net of capital costs and the student/teacher ratio) was strongly positive.

Thus one hypothesis for the pattern of results shown in Table IV is that compensatory resource allocation toward highminority high schools in CMS mitigated the effect of rezoning on academic outcomes in later cohorts. As a partial test of this hypothesis, we include PctMinority izjc $_{c}$ along with time-varying resources in a "horse race" specification. We calculate resource measures based on the teachers in each student's high school averaged across all post-rezoning years that the student was still enrolled. We calculate the resource measures based on students assigned rather than actual school because it mimics the construction of PctMinority $y_{i z j c}$ and the logic of our identification strategy. Because both measures vary only at the school cohort level, this effectively asks whether the impact of changing peer composition can be explained by changes in resource allocation across schools and over time.

The top panel of Table $\mathrm{V}$ shows specifications where PctMinority $_{i z j c}$ is entered along with the percent of teachers with a bachelor's degree from a selective college, and the bottom panel shows separate specifications where PctMinority Pzjc $_{\text {is }}$ entered along with per-pupil teacher wages. Clotfelter et al. (2010) find that the selectivity of undergraduate institution has a statistically significant and positive effect on achievement among high school students in North Carolina. Looking at effects on high test scores in column (1), we see that the negative effects in Table III can be explained completely by changes in resources. The coefficients for PctMinority $y_{i z j c}$ are positive and insignificantly different from zero for both resource measures. The pattern of results is very similar for college attendance in column (2). We

17. Mean per-pupil spending on teacher salaries in CMS high schools was $\$ 3,494$ in $2001-2$ with a standard deviation of only $\$ 354$. In $2002-3$, the mean was $\$ 3,652$ but the standard deviation rose to $\$ 583$. In $2006-7$, mean per-pupil spending on teacher salaries had risen to $\$ 5,313$ (this includes the incentive money from the High School Challenge) with a standard deviation of $\$ 1,219$. 
TABLE V

Correlation between Main Results and Time-Varying School Resources

\begin{tabular}{lccc}
\hline \hline & $(1)$ & $(2)$ & $(3)$ \\
& $\begin{array}{c}\text { HS test } \\
\text { scores }\end{array}$ & $\begin{array}{c}\text { Attend } \\
\text { 4-year college }\end{array}$ & $\begin{array}{c}\text { Ever } \\
\text { incarcerated }\end{array}$ \\
\hline Panel A: All cohorts & & & \\
All students: & & & \\
$\quad$ Share minority in new school zone & 0.015 & -0.014 & 0.006 \\
& {$[0.048]$} & {$[0.022]$} & {$[0.017]$} \\
\% Teacher BA, selective coll. & $0.545^{* *}$ & $0.335^{* *}$ & 0.066 \\
& {$[0.242]$} & {$[0.141]$} & {$[0.089]$} \\
& & & \\
Panel B: All cohorts & & & \\
All students: & & & \\
Share minority in new school zone & 0.013 & -0.017 & 0.007 \\
& {$[0.047]$} & {$[0.022]$} & {$[0.017]$} \\
Teacher salary per pupil (in $\$ 1000 \mathrm{~s})$ & $0.018^{* * *}$ & $0.017^{* * *}$ & $-0.012^{* * *}$ \\
& {$[0.007]$} & {$[0.004]$} & {$[0.003]$} \\
Observations & 30,498 & 38,037 & 38,037 \\
\hline \hline
\end{tabular}

Notes. Within panels, each column shows coefficients and standard errors from a separate estimate of equation (1), and is interpreted as the effect of being assigned to a school with 100 percentage points more minority students, where the effect is allowed to vary by race as indicated in each row. Both share minority and the indicated school-level teacher characteristic are included in the regression together, to see if resources can "explain" away the effect of school racial composition. Panel A includes a measure of the share of teachers with a degree from a selective college, and Panel B includes an alternative measure of resources-teacher salaries per pupil enrolled. All regressions control for race by cohort fixed effects, parcel group by prior middle and high school zone fixed effects, and quadratics in fifth-grade math and reading scores plus dummies for missing scores. Teacher characteristics are averaged across all post-rezoning years in which a student was enrolled. Column (1) is the average across all nonmissing high school test scores in English I, algebra I, geometry, and algebra II. College attendance records are obtained from the NSC data and criminal records are obtained from the Mecklenburg County Sheriff; both can track students who leave CMS schools. We define "minority" as black and Hispanic students, and "nonminority" as all other ethnicities (including whites). Standard errors are clustered at the prior zone and new zone by parcel group levels, using the multiway clustering procedure of Cameron et al. (2011). ${ }^{* * *} p<.01, * * p<.05,{ }^{*} p<.10$.

can interpret these estimates as suggesting that there is no effect of increases in assigned school share minority on academic outcomes when resources are equalized across schools. Nevertheless, we find no significant correlation between teacher education and the effects on crime, and the coefficient on per-pupil wages, while statistically significant, is about $50 \%$ smaller than the effects for academic outcomes.

It is important to note that this evidence does not demonstrate the causal effect of teacher characteristics or teacher salaries, because changes in these resource measures could be correlated with changes in other unobserved determinants of school quality, such as peer characteristics. Still, these results provide some qualified support for the hypothesis that changes in resource allocation can explain the pattern of effects over time. 
Additional evidence that the pattern of results might be explained by academic improvements in high-minority schools over the period we study can be found in data on measures of upper level and advanced placement (AP) course-taking (Online Appendix Table A18). For students in the high school cohorts, being assigned to a school with more minority students led to decreased enrollment in honors and advanced math courses (defined as precalculus and above), as well as decreases in the probability of taking an AP science or English course. However, we find no impact on advanced course-taking for the youngest group of students.

\section{VI.B. Peer Effects}

If most of the effect of school segregation were driven by associated changes in resources-either financial or in terms of nonfinancial inputs such as teacher quality-then policy makers could address racial inequality directly through compensatory policies (such as the High School Challenge), rather than manipulating student assignment directly. However, a fourth possible explanation is that the rezoning of CMS schools led to changes in peer interactions and/or school context. Unlike the allocation of resources, peer interactions and school context may be very difficult for a school district to manipulate.

Because race, poverty, and test scores are strongly correlated, the rezoning of CMS schools also widened inequality by family income and prior achievement. In Table VI we attempt to disentangle the separate influences of each attribute by estimating another horse race specification that adds all three measures of changes in peers to equation (1), in the spirit of Cutler and Glaeser (1997) and Hoxby and Weingarth (2006). This specification identifies off of the independent variation across student attributes (i.e., poor whites, nonpoor minorities, high-scoring poor students, etc.). We also report the $p$-values on $F$-tests for the joint hypotheses that (1) all three coefficients (race, income, test scores) are equal to zero, and (2) all three coefficients are equal to each other. The first test measures whether changes in peers have any net effect on the outcomes in each column. The second test measures whether the peer attributes are significantly different from each other.

Our main results are robust to including all peer attributes in the model together. We fail to reject the joint hypotheses that all 
TABLE VI

Peer Effects: Which Characteristics Matter?

\begin{tabular}{lccc}
\hline \hline & $(1)$ & $(2)$ & $(3)$ \\
& $\begin{array}{c}\text { HS test } \\
\text { scores }\end{array}$ & $\begin{array}{c}\text { Attend } \\
\text { 4-year college }\end{array}$ & $\begin{array}{c}\text { Ever } \\
\text { incarcerated }\end{array}$ \\
\hline All cohorts combined & & & \\
Pct minority in new school zone for: & & & \\
Nonminority student & 0.016 & -0.049 & 0.322 \\
& {$[0.166]$} & {$[0.102]$} & {$[0.208]$} \\
Minority student & -0.043 & -0.082 & 0.265 \\
& {$[0.146]$} & {$[0.080]$} & {$[0.226]$} \\
Pct. free lunch in new school zone for: & & & \\
Nonminority student & $-0.366^{* *}$ & -0.131 & -0.247 \\
& {$[0.163]$} & {$[0.103]$} & {$[0.183]$} \\
Minority student & -0.110 & -0.122 & -0.189 \\
& {$[0.137]$} & {$[0.084]$} & {$[0.187]$} \\
Avg. math scores in new school zone for: & & \\
Nonminority student & $-0.291^{* * *}$ & $-0.087^{* *}$ & -0.034 \\
& {$[0.063]$} & {$[0.038]$} & {$[0.084]$} \\
Minority student & $-0.142^{*}$ & $-0.183^{* * *}$ & -0.004 \\
& {$[0.075]$} & {$[0.039]$} & {$[0.086]$} \\
& & & \\
$F$ (all coeffs =0), nonminority & 0.000 & 0.019 & 0.355 \\
$F$ (all coeffs = 0), minority & 0.221 & 0.000 & 0.096 \\
$F$ (all coeffs equal), nonminority & 0.000 & 0.026 & 0.280 \\
$F$ (all coeffs equal), minority & 0.221 & 0.001 & 0.172 \\
Observations & 31,675 & 43,949 & 43,949 \\
\hline \hline
\end{tabular}

Notes. Each column shows coefficients and standard errors from a separate estimate of equation (1), and is interpreted as the effect of being assigned to a school with 100 percentage points more students of each type (race, free lunch eligible), or a 1 standard deviation increase in fifth-grade math scores, holding the other two peer characteristics constant. The effect is also allowed to vary by student's own race as indicated in each row. All regressions control for race by cohort fixed effects, parcel group by prior middle and high school zone fixed effects, and quadratics in fifth-grade math and reading scores plus dummies for missing scores. The two rows immediately below the coefficients report $p$-values on $F$-tests of the hypothesis that the three peer characteristics are jointly equal to 0 , for nonminorities and minorities, respectively. This tests whether peers "matter" for the indicated outcomes. The next two rows report $p$-values on $F$-tests for the hypothesis that the peer characteristics are jointly equal to each other. This tests whether peer characteristics can be separated into independent influences. Column (1) is the average across all nonmissing high school test scores in English I, algebra I, geometry, and algebra II. College attendance records are obtained from the NSC data and criminal records are obtained from the Mecklenburg County Sheriff; both can track students who leave CMS schools. Standard errors are clustered at the prior zone and new zone by parcel group levels, using the multiway clustering procedure of Cameronet al. (2011). $* * * p<.01, * * p<.05, * p<.10$.

coefficients are equal to zero for the same set of outcomes and groups that were significantly different from zero in the main results. For crime, we also cannot reject equality of effects across the three peer attributes. In other words, attending a school with more minority children has roughly the same effect as attending a school with more poor or lower scoring children. 
However, conditional on peer race and poverty status, attending a school with higher scoring children actually lowers students' own test scores and makes them less likely to attend college. This pattern is stronger among whites for test scores and stronger among minorities for four-year college attendance. This surprising result implies, for example, that students of all races benefit the most academically from exposure to more lowscoring, nonpoor whites, and that they benefit the least from exposure to high-scoring, poor minorities. One possible mechanism is high school course tracking, which limits access to college-level courses to the highest scoring students within a school, or the "frog pond" effect of increased competition and class rank (Attewell 2001; Crosnoe 2009). Thus the offsetting effects of peer race/income and peer prior achievement may have limited the effect of rezoning on inequality, at least for academic outcomes.

Table VII presents results for minority males where the effect of PctMinority ${ }_{i z j c}$ is allowed to vary by share minority of the student's 2000 CBG (other groups are included in the model but the coefficients are not reported). ${ }^{18} \mathrm{We}$ find no evidence of nonlinearities for academic outcomes. However, the results for crime are highly nonlinear and indicate that nearly all of the effect on crime is driven by minority males who live in neighborhoods that are $60 \%$ minority or greater. Thus the overall effect on crime is driven by relatively high concentrations of minority males being grouped together. A number of studies find support for the notion that concentrations of minority males increase crime in the aggregate (Cook and Ludwig 2006; Carrell and Hoekstra 2010; Bifulco, Fletcher and Ross 2011; Deming 2011; Imberman et al. 2012). Mechanisms by which this might occur are suggested by Weinberg (2007), who estimates a model of endogenous peer group association and finds that concentrations of like-minded individuals will increase connectedness among them, and by Fletcher et al. (2013), who show that increasing racial segregation leads to a reduction in cross-race friendships.

Finally, in Online Appendix Table A19, we report results from a specification where we allow the effect of rezoning to vary across eight combinations of own income, peer race, and

18. We cannot directly stratify the analysis by school racial composition because our analysis compares students on either side of a newly drawn school boundary, and stratifying by school race would eliminate the identifying variation. 
TABLE VII

Heterogeneity by Neighborhood Composition

\begin{tabular}{|c|c|c|c|}
\hline & $\begin{array}{c}(1) \\
\text { HS test } \\
\text { scores }\end{array}$ & $\begin{array}{c}(2) \\
\text { Attend } \\
\text { 4-year college }\end{array}$ & $\begin{array}{c}(3) \\
\text { Ever } \\
\text { incarcerated }\end{array}$ \\
\hline \multicolumn{4}{|c|}{ Impact on minority males who live in neighborhoods that are: } \\
\hline 0 to $20 \%$ minority & $\begin{array}{c}-0.062 \\
{[0.176]}\end{array}$ & $\begin{array}{c}0.174^{*} \\
{[0.091]}\end{array}$ & $\begin{array}{c}-0.049 \\
{[0.049]}\end{array}$ \\
\hline 20 to $40 \%$ minority & $\begin{array}{c}-0.054 \\
{[0.129]}\end{array}$ & $\begin{array}{l}0.09 \\
{[0.058]}\end{array}$ & $\begin{array}{c}0.068 \\
{[0.044]}\end{array}$ \\
\hline 40 to $60 \%$ minority & $\begin{array}{c}-0.045 \\
{[0.146]}\end{array}$ & $\begin{array}{c}0.116^{*} \\
{[0.067]}\end{array}$ & $\begin{array}{c}-0.076 \\
{[0.060]}\end{array}$ \\
\hline 60 to $80 \%$ minority & $\begin{array}{c}-0.184 \\
{[0.142]}\end{array}$ & $\begin{array}{c}0.044 \\
{[0.039]}\end{array}$ & $\begin{array}{c}0.071^{*} \\
{[0.044]}\end{array}$ \\
\hline 80 to $100 \%$ minority & $\begin{array}{c}-0.115 \\
{[0.083]}\end{array}$ & $\begin{array}{c}0.031 \\
{[0.032]}\end{array}$ & $\begin{array}{c}0.071^{* *} \\
{[0.033]}\end{array}$ \\
\hline$F($ all quintiles equal) & 0.922 & 0.471 & 0.006 \\
\hline Observations & 43,949 & 43,949 & 43,949 \\
\hline
\end{tabular}

Notes. Each column shows coefficients and standard errors from a separate estimate of equation (1), where the results are interpreted as the effect of being assigned to a school with a 100 percentage point greater share of students in the demographic group indicated in each row. The effects are allowed to vary by five categories (indicated in each row) of the percent of minority residents in a student's 2000 Census block group. Results are pooled by grade cohort. All regressions control for race by cohort fixed effects, parcel group by prior middle and high school zone fixed effects, and quadratics in fifth-grade math and reading scores plus dummies for missing scores. Column (1) is the average across all nonmissing high school test scores in English I, algebra I, geometry, and algebra II. College attendance records are obtained from the NSC data and criminal records are obtained from the Mecklenburg County Sheriff; both can track students who leave CMS schools. Standard errors are clustered at the prior zone and new zone by parcel group levels, using the multiway clustering procedure of Cameron et al. (2011). $* * * p<.01$, $* * p<.05, * p<.10$.

peer income. We find that poor minority males have higher rates of criminal involvement when they are grouped together with other poor minority males, and that crime is not significantly affected among any other groups for any combinations of demographic changes. Combined with the evidence from Table VII, this suggests that crime increases nonlinearly when poor minority males are concentrated together in the same schools.

Changes in school context could also come from institutional reactions to peer group composition. Kinsler (2011) shows that although black students are about twice as likely to be suspended from school compared to white students, all of the racial gap in school discipline is driven by variation across (rather than within) schools. Thus it is possible that students who are assigned to schools with more minority students exhibit similar behavior but are treated differently. If schools with more poor and minority 
students have a greater police presence, for example, this would raise the probability of disciplinary action conditional on behavior. If school suspensions lead to long-run increases in crime, then differences in schools' treatment of student behavior could explain our findings. However, we find no effect on out-of-school suspensions (not shown), which is important because all arrests stemming from behavior on school grounds also result in the student being suspended. This suggests that our crime results are not driven by criminal offenses that occur on school grounds.

A final possible explanation for the results is that neighborhoods changed over time, which in turn affected school context. Weinstein (2011) and Liebowitz and Page (2012) study neighborhood change in Charlotte following the end of busing. Weinstein (2011) finds that a 10 percentage point increase in the percent black of an assigned elementary school led to a 0.4 percentage point change in the percent minority of the neighborhood five years after busing. However, this relatively small change is unlikely to explain much of our results.

\section{CONCLUSION}

Few would argue today with the basic argument laid out in Brown v. Board of Education that state-enforced segregation through "separate but equal" is unconstitutional and inequitable. Yet the remedy authorized later by Swann v. Mecklenburg County Schools of forced busing proved controversial and difficult to enforce (Armor and Rossell 2002). The end of court-ordered school desegregation has led to concerns that subsequent resegregation of schools will reverse some of the gains made by blacks in the 1960s and 1970s (e.g., Mickelson 2003).

We find that the resegregation of CMS schools led to an increase in racial inequality. Both whites and minorities score lower on high school exams when they are assigned to schools with more minority students. Our estimates imply that rezoning in CMS widened the racial gap in math scores by about 0.025 standard deviation. Similarly, we find that white students are about 1 percentage point less likely to graduate from high school or attend a four-year college when they are assigned to schools with 10 percentage points more minority students. Finally, we find that rezoning in CMS led to a large and persistent increase in criminal activity among minority males-a 10 
percentage point increase in share minority of a minority male's assigned school led to an increase in the probability of incarceration of about 1.3 percentage points.

We also find that the effect of school segregation on academic outcomes was larger for older cohorts, who were either in or entering high school when busing ended. We present suggestive evidence that increases over time in resource allocation to highminority high schools in CMS may explain this pattern. However, the effects on crime do not diminish over time and remain large nine years after the rezoning. Moreover, these effects are concentrated among poor minority males from highly segregated neighborhoods.

Our findings suggest that explicit efforts may be necessary if policy makers wish to prevent a widening of racial and economic inequality in the wake of increases in school segregation. CMS implemented a number of innovative policy changes over the past decade, including the allocation of additional resources to and intensive monitoring of high schools with concentrations of minority students. These efforts may have played some role in halting an initial widening of racial inequality in academic outcomes. However, if peer effects are responsible for increases in crime among minority males, then widening racial inequality in crime may be linked inextricably with segregation. Policies that allocate additional resources to segregated schools can improve classroom instruction and course offerings, but only deliberately integrative student assignment policies can change the racial or socioeconomic composition of students who walk in the doors of the school.

UNIVERSITY OF NORTH CAROLINA-CHARLOTTE

HARVARD GRADUATE SCHOOL OF EDUCATION

COLUMBIA GRADUATE SCHOOL OF BUSINESS

\section{SUPPLEMENTARY MATERIAL}

An Online Appendix for this article can be found at QJE online (qje.oxfordjournals.org).

\section{REFERENCES}


Armor, David J., and C. H. Rossell, "Desegregation and Resegregation in the Public Schools," in Beyond the Color Line: New Perspectives on Race and Ethnicity in America, A. Thernstrom and S. Thernstrom, eds. (Stanford, CA: Hoover Institution Press, 2002), 219-258.

Ashenfelter, Orley, William J. Collins, and Albert Yoon, "Evaluating the Role of Brown vs. Board of Education in School Equalization, Desegregation, and the Income of African Americans," American Law and Economics Review, 8 (2006), 213-248.

Attewell, Paul, "The Winner-Take-All High School: Organizational Adaptations to Educational Stratification," Sociology of Education, 74, no. 4 (2001), 267-295.

Bayer, Patrick, Fernando Ferreira, and Robert McMillan, "A Unified Framework for Measuring Preferences for Schools and Neighborhoods," Journal of Political Economy, 115, no. 4 (2007), 588-638.

Bifulco, Robert, Jason M. Fletcher, and Stephen L. Ross, "The Effect of Classmate Characteristics on Post-Secondary Outcomes: Evidence from the Add Health," American Economic Journal: Economic Policy, 3, no. 1 (2011), $25-53$.

Black, Sandra, "Do Better Schools Matter? Parental Valuation of Elementary Education," Quarterly Journal of Economics, 114 (1999), 577-599.

Cameron, A. Colin, Jonah B. Gelbach, and Douglas L. Miller, "Robust Inference with Multiway Clustering," Journal of Business and Economic Statistics, 29, no. 2 (2011), 238-249.

Card, David, and Alan B. Krueger, "Does School Quality Matter? Returns to Education and Characteristics of Public School in the United States," Journal of Political Economy, 100, no. 1 (1992), 1-40.

Card, David, and Jesse Rothstein, "Racial Segregation and the Black-White Test Score Gap," Journal of Public Economics, 91 (2007), 2158-2184.

Carrell, Scott E., and Mark L. Hoekstra, "Externalities in the Classroom: How Children Exposed to Domestic Violence Affect Everyone's Kids," American Economic Journal: Applied Economics, 2, no. 1 (2010), 211-228.

Cascio, Elizabeth, Nora Gordon, Ethan Lewis, and Sarah Reber, "Paying for Progress: Conditional Grants and the Desegregation of Southern Schools," Quarterly Journal of Economics, 125 (2010), 445-482.

Chetty, Raj, John N. Friedman, Nathaniel Hilger, Emmanuel Saez, Diane Whitmore Schanzenbach, and Danny Yagan, "How Does Your Kindergarten Classroom Affect Your Earnings? Evidence from Project STAR," Quarterly Journal of Economics, 126 (2011), 1593-1660.

Clotfelter, Charles T., Helen F. Ladd, and Jacob L. Vigdor, "Teacher Credentials and Student Achievement in High School: A Cross-Subject Analysis with Student Fixed Effects," Journal of Human Resources, 45, no. 3 (2007), 655-681.

CMS Schools, "High School Challenge Update," public presentation made to the Mecklenburg County Board of Education, dated December 13, 2005.

, "Update on High School Challenge," press release by CMS Schools, October 15, 2008.

Cook, Michael D., and William N. Evans, "Families or Schools? Explaining the Convergence in White and Black Academic Performance," Journal of Labor Economics, 18, no. 4 (2000), 729-754.

Cook, Philip J., and Jens Ludwig, "Assigning Youths to Minimize Total Harm," in Deviant Peer Influences in Programs for Youth, Kenneth A. Dodge, Joan McCord, Thomas J. Dishion, and Jennifer E. Lansford, eds. (New York: The Guilford Press, 2006), 67-89.

Crosnoe, Robert, "Low Income Students and the Socioeconomic Composition of Public High Schools," American Sociological Review, 74, no. 5 (2009), 709-730.

Cutler, David M., and Edward L. Glaeser, "Are Ghettos Good or Bad?," Quarterly Journal of Economics, 112 (1997), 827-872.

Deming, David J., "Better Schools, Less Crime?," Quarterly Journal of Economics, 126 (2011), 2063-2115.

Deming, David J., Justine S. Hastings, Thomas J. Kane, and Douglas O. Staiger, "School Choice, School Quality and Postsecondary Attainment," NBER Working Paper No. 17438, 2013. 
Dobbie, Will, and Roland G. Fryer, "Are High-Quality Schools Enough to Close the Achievement Gap? Evidence from a Bold Social Experiment in Harlem," American Economic Journal: Applied Economics (2013), forthcoming.

Fletcher, Jason, Stephen Ross, and Yuxiu Zhang, "The Determinants and Consequences of Friendship Composition," unpublished working paper, 2013.

Guryan, J., "Desegregation and Black Dropout Rates," American Economic Review, 94 (2004), 919-943.

Hanushek, E., J. F. Kain, and S. Rivkin, "New Evidence about Brown v. Board of Education: The Complex Effects of School Racial Composition on Achievement," Journal of Labor Economics, 27 (2009), 349-383.

Hastings, Justine S., Thomas J. Kane, and Douglas O. Staiger, "Heterogeneous Preferences and the Efficacy of Public School Choice," working paper, 2008.

Hoxby, Caroline, "Peer Effects in the Classroom: Learning from Gender and Race Variation," NBER Working Paper No. 7867, 2000.

Hoxby, Caroline M., and Gretchen Weingarth, "Taking Race out of the Equation: School Reassignment and the Structure of Peer Effects," Working Paper, 2006.

Imberman, Scott, Adriana D. Kugler, and Bruce Sacerdote, "Katrina's Children: Evidence on the Structure of Peer Effects from Hurricane Evacuees," American Economic Review, 102, no. 5 (2012), 2048-2082.

Jackson, C. Kirabo, "Student Demographics, Teacher Sorting, and Teacher Quality: Evidence from the End of School Desegregation," Journal of Labor Economics, 27, no. 2 (2009), 213-256.

Johnson, Rucker C., "Long-Run Impacts of School Desegregation \& School Quality on Adult Attainments," NBER Working Paper No. 16664, 2011.

Kane, Thomas J., Douglas O. Staiger, and Stephanie K. Riegg, "School Quality, Neighborhoods, and Housing Prices: The Impacts of School Desegregation," NBER Working Paper No. 11347, 2005.

Katz, Lawrence F., Jeffrey R. Kling, and Jeffrey B. Liebman, "Moving to Opportunity in Boston: Early Results of a Randomized Mobility Experiment," Quarterly Journal of Economics, 116 (2001), 607-654.

Kinsler, Josh, "Understanding the Black-White School Discipline Gap," Economics of Education Review, 30 (2011), 1370-1383.

Kling, Jeffrey R., Jeffrey B. Liebman, and Lawrence F. Katz, "Experimental Analysis of Neighborhood Effects," Econometrica, 75, no. 1 (2007), 83-119.

Liebowitz, David, and Lindsay Page, "Is School Policy Housing Policy? Evidence from the End of Desegregation in Charlotte-Mecklenburg," unpublished working paper, 2012.

Linden, Leigh, and Jonah Rockoff, "Estimates of the Impact of Crime Risk on Property Values from Megan's Laws," American Economic Review, 98, no. 3 (2008), 1103-1127.

Ludwig, Jens O., Jeffrey R. Kling, and Lawrence F. Katz, "Neighborhood Effects on Crime for Female and Male Youth: Evidence from a Randomized Housing Voucher Experiment," Quarterly Journal of Economics, 120 (2005), 87-130.

Lutz, Byron, "The End of Court-Ordered Desegregation," American Economic Journal: Economic Policy, 3, no. 2 (2011), 130-168.

Margo, Robert A. Race and Schooling in the U.S. South 1880-1950: An Economic History (Chicago: University of Chicago Press, 1990).

Massey, Douglas, and Nancy Denton, "The Dimensions of Residential Segregation," Social Forces, 67 (1988), 281-315.

Mickelson, Roslyn A., "The Academic Consequences of Desegregation and Segregation: Evidence from the Charlotte-Mecklenburg Schools," North Carolina Law Review, 81 (2003), 1513-1562.

Mickelson, Roslyn A., Stephen S. Smith, and Stephanie Southworth, "Resegregation, Achievement, and the Chimera of Choice in Post-Unitary Charlotte-Mecklenburg Schools," in From the Courtroom to the Classroom: The Shifting Landscape of School Desegregation, C. E. Smrekar and E. B. Goldring, eds. (Cambridge, MA: Harvard University Press, 2009), 129-156.

NAACP Legal Defense and Education Fund, 2000 Annual Report (New York: NAACP, 2000). 
Reardon, Sean F., Elena Tej Grewal, Demetra Kalogrides, and Erica Greenberg, "Brown Fades: The End of Court-Ordered School Desegregation and the Resegregation of American Public Schools," Journal of Policy Analysis and Management, 31, no. 4 (2012), 876-904.

Reber, Sarah J., "School Desegregation and Educational Attainment for Blacks," Journal of Human Resources, 45, no. 4 (2010).

Rossell, Christine, and David Armor, "The Effectiveness of School Desegregation Plans, 1968-1991," American Politics Quarterly, 24, no. 3 (1996), 267-302.

Smith, Stephen S. Boom for Whom? Education, Desegregation and Development in Charlotte (Albany: SUNY Press, 2004).

Vigdor, J. L., and J. O. Ludwig, "Segregation and the Test Score Gap," in Steady Gains and Stalled Progress: Inequality and the Black-White Test Score Gap, K. Magnuson and J. Waldfogel, eds. (New York: Russell Sage Foundation, 2008).

Weinberg, Bruce A., "Social Interactions with Endogenous Associations," NBER Working Paper No. 13038, 2007.

Weiner, David A., Byron F. Lutz, and Jens Ludwig, "The Effects of School Desegregation on Crime," NBER Working Paper No. 15380, 2009.

Weinstein, Jeffrey M., "The Impact of School Racial Compositions on Neighborhood Racial Compositions: Evidence from School Redistricting," working paper, 2011. 